\title{
Hepatic stereology of schistosomiasis mansoni infected-mice fed a high-fat diet
}

\author{
Renata Heisler Neves**, Alba Cristina Miranda de Barros Alencar, \\ Marcia Barbosa Aguila*, Carlos Alberto Mandarim-de-Lacerda*, \\ José Roberto Machado-Silva/ ${ }^{+}$, Delir Corrêa Gomes**
}

\begin{abstract}
Laboratório de Helmintologia Romero Lascasas Porto, Disciplina de Parasitologia, Departamento de Patologia e Laboratórios, Faculdade de Ciências Médicas * Laboratório de Morfometria e Morfologia Cardiovascular, Instituto de Biologia, Universidade do Estado do Rio de Janeiro, Av. Prof. Manoel de Abreu 444, 20551-170 Rio de Janeiro, RJ, Brasil **Laboratório de Helmintos Parasitos de Vertebrados, Departamento de Helmintologia, Instituto Oswaldo Cruz-Fiocruz, Rio de Janeiro, RJ, Brasil
\end{abstract}

High-fat diets induce weight gain and fatty liver in wild-type mice. Schistosomiasis mansoni infection also promotes hepatic injury. This study was designed to quantify hepatic alterations in schistosomiasis mansoni-infected mice fed a high fat-rich chow compared to mice fed a standard rodent chow, using stereology. Female SW mice fed each either high-fat diet (29\% lipids) or standard chow (12\% lipids) over 8 months, and then were infected with Schistosoma mansoni cercariae. Four experimental groups were studied: infected mice fed a high-fat diet (IHFC) or standard chow (ISC), uninfected mice fed a high-fat diet (HFC) or standard chow (SC). Mice were sacrificed during early infection (9 weeks from exposure). The following hepatic biometry and the stereology parameters were determined: volume density (hepatocytes [h], sinusoids [s], steatosis [st] and hepatic fibrosis [hf]); numerical density (hepatocyte nuclei $-N v[h]$ ); absolute number of total hepatocyte $N[h]$, normal hepatocyte $N[n h]$, and binucleated hepatocyte N[bh], percentage of normal hepatocyte P [nh] and binucleated hepatocyte P[bh]. IHFC and HFC groups exhibited TC, $H D L-C, L D L-C$, and body mass significantly greater $(p<0.05)$ than control group. No significant differences were found regards liver volume $(p=0.07)$. Significant differences were observed regards $P[n h](p=0.0045), P[b h](p=0.0045), N v[h](p=0.0006), N[h](p=0.0125), N[b h](p=0.0164)$ and $N[n h]$ $(p=0.0078)$. IHFC mice group presented $29 \%$ of binucleated hepatocytes compared to HFC group (19\%), ISC group (17\%) and SC (6\%). Volume density was significantly different between groups: Vv[h] ( $p=0.0052), V v[s](p$ $=0.0025), V v[s t](p=0.0004)$, and $V v[h f](p=0.0007)$. In conclusion, schistosomiasis mansoni infection with concurrent high-fat diet promotes intensive quantitative changes in hepatic structure, contributing to an increasing on hepatic regeneration.

Key words: Schistosoma mansoni - stereology - liver - high-fat diet - mice

Diet-induced models have proven beneficial for the evaluation of physiological changes that take place on the diseases pathogenesis. Dietary factors promote obesity and obesity-related disorders, such as fatty liver disease ( $\mathrm{Li}$ et al. 2005). Obesity is also predictive of the presence of fibrosis, potentially progressing to advanced liver disease (Festi et al. 2004). Schistosomiasis mansoni infection also promotes liver injury in both humans and mice yet a granulomatous inflammation is formed around mature egg (Hogan et al. 2002, Stavitsky 2004). In the former, liver dysfunction, dyslipidemia, and protein alteration are common findings (Lima et al. 1998).

The liver is remarkable in its ability to regenerate itself after acute injury. Rapid biochemical and gene expression changes following initiation of regeneration are mediated by specific stimuli, including growth factors and cytokines (Michalopoulos \& DeFrances 2005). The liver maintains a functional cell mass consisting of several specialized cell

Financial support: Faperj, Capes, CNPq +Corresponding author: machado@uerj.br Received 25 May 2006

Accepted 26 June 2006 types, of which the hepatocytes form the major part (Zimmermann 2004). However, animals submitted to a highfat diet and the subsequent development of steatosis predisposes to hepatic injury (Zhang et al. 1999, Rao et al. 2001, Picard et al. 2002, DeAngelis et al. 2005). Earlier studies evaluated hepatic regeneration in murine experimental schistosomiasis. It does appear that extensive schistosomal lesions do not impair hepatic cell regeneration (Teixeira $\&$ Andrade 1985). In addition, partial hepatectomy represents a considerable stimulus for the regenerative capacity of the liver during acute schistosomiasis (Zucoloto et al. 1990, Costa et al. 1999).

Most research on liver in schistosomiasis mansoni infection has focused on histological changes (Andrade \& De Azevedo 1987, Lenzi et al. 1998, Baptista \& Andrade 2005) despite quantitative aspects of liver structure have been also studied (Silva et al. 2000). In recent years, stereology has been extensively used as a standardized and quantitative tool in liver injuries relating to clinical studies (Franzen et al. 2005, Lazzarini et al. 2005) and experimental evaluation of nutritional effects of high-fat diet (Aguila et al. 2003). However, its application in schistosomiasis mansoni has been little explored. Stereological analysis revealed that mice peak granuloma formation was already reached 8 days after injection of Sepharose beads in single-sex infected mice compared with 16 days in na- 
ive animals (Jacobs et al. 1997). Zinc-deficient mice infected with Schistosoma mansoni had more eggs trapped in the livers, smaller median liver volume and median granuloma volume per eggs than well-fed diet mice (Friis et al. 1998). Surprisingly, hepatic alterations in simultaneous schistosomiasis and fatty liver disease are unknown. The aim of this work is to quantify hepatic alterations in schistosomiasis mansoni-infected mice fed a high fat-rich diet.

\section{MATERIALS AND METHODS}

Animals - Female Swiss Webster mice ( 3 wk old) were obtained from the Laboratory Animals Breeding Center (Oswaldo Cruz Foundation, Brazil) and appropriatedly housed. Mice were kept in a temperature $\left(21 \pm 1^{\circ} \mathrm{C}\right)$ and humidity-controlled $(60 \pm 10 \%)$ room, exposed to a $12 \mathrm{~h}$ light and dark cycle (artificial lights) and to an air exhaustion cycle. All animal procedures were in accordance with the ethical procedures with investigated animals and were approved by the Oswaldo Cruz Foundation Animal Ethics Committee (PO105-02).

Diets - In experimental groups mice fed a high-fat chow $(\mathrm{n}=10)$ containing lard, egg yolks, wheat flour, corn starch, casein and vitamins, and minerals mixture ( $47 \%$ carbohydrates, $24 \%$ proteins, $29 \%$ lipids $)(5.7 \mathrm{kcal} / \mathrm{g}$ body wt./ day) (Aguila et al. 2002) over a period of 8 months. The ingredients were purchased from commercial sources and were weekly prepared in our laboratory and stored at $+4^{\circ} \mathrm{C}$. The major ingredient proportions and the total combustible energy $(\mathrm{kj} / \mathrm{kg}$ and $\mathrm{kcal} / \mathrm{kg})$ of experimental diet are shown in Table I. Standard mice chow group $(n=10)$ fed a commercial standard chow (Nuvilab, Paraná, Brazil) containing $12 \%$ fat, $28 \%$ protein, and $60 \%$ carbohydrate ( 4.6 $\mathrm{kcal} / \mathrm{g}$ body mass/day). All animals had free access to water and food throughout the experiment.

Biochemical parameters - One day before the end of the experiment, mice were food-deprived overnight before blood collection. Blood samples were obtained by puncture of the retro orbital sinus. The following biochemical parameters were analyzed: total cholesterol (TC), triglycerides (TG), low-density lipoprotein cholesterol (LDL-C), high-density lipoprotein cholesterol (HDL-C), and very-long-density lipoprotein cholesterol (VLDL-C).

Experimental groups - Mice were submitted to each diet for six months, and then were infected with $50 \mathrm{~S}$. mansoni cercariae each (BH strain, Brazil). Animals were divided into four experimental groups: infected mice fed a high fat chow (IHFC) or a standard chow (ISC); uninfected mice fed a high fat chow (HFC) or a standard chow (SC).

Tissue processing - Mice were sacrificed by cervical dislocation 9 weeks from exposure (during early infection). The liver was removed, the liver mass (LM) and liver volume (LV) were measured using immersion method (Scherle 1970). Liver specimens were separated into several minor fragments kept for $48 \mathrm{~h}$ at room temperature in a fixative (modified Millonig's phosphate-buffered formalin, pH 7.4) (Carson et al. 1973), embedded in paraffin, sectioned at $5 \mu \mathrm{m}$ thickness, and the sections were stained with Masson's trichrome.
TABLE I

Composition of the experimental diet $(\mathrm{g} / \mathrm{kg})$

\begin{tabular}{lr}
\hline Components & Quantity \\
\hline Casein & 305 \\
Corn starch & 150 \\
Wheat flour & 245 \\
Egg yolk & 180 \\
Lard & 120 \\
Total & 1,000 \\
Vitamin mixture $(\mathrm{mg})^{a}$ & 50 \\
Mineral mixture $(\mathrm{mg})^{b}$ & 30 \\
Cholesterol $_{\text {Kcal/kg }}$ & 3 \\
Kj/kg & 5,734 \\
Saturated fatty acids & 23,968 \\
Monounsaturated fatty acids & 354 \\
Polyunsaturated fatty acids & 500 \\
\end{tabular}

$a$ : vitamin mixture: $50 \mathrm{mg}$. Vitamins (per kg of diet): thiamine, 6.5 $\mathrm{mg}$; riboflavin, $5.3 \mathrm{mg}$; pyridoxine, $6.3 \mathrm{mg}$; niacin, $7.5 \mathrm{mg}$; folic acid, $1.3 \mathrm{mg}$; biotin, $0.5 \mathrm{mg}$; cyanocobalamin, $0.19 \mathrm{mg}$; retinyl palmitate, $1562 \mathrm{UI}$; cholecalciferol, $1250 \mathrm{UI}$; tocopheryl acetate, $81.3 \mathrm{mg}$; ascorbic acid, $185 \mathrm{mg}$. $b$ : mineral mixture: $30 \mathrm{mg}$. Minerals (mg per kg of diet): calcium, 6000; phosphorus, 5000; sodium, 500; potassium, 1800; chlorine, 500; magnesium, 400; manganese, 50; iron, 35; zinc, 29; copper, 5; fibers, $11.5 \mathrm{~g}$.

Stereological study - The liver was analyzed considering the hepatocytes, the sinusoids, steatosis, and the hepatic fibrosis. The hepatic fragments (minimum of three fragments per animal) were embedded together and faced to be cut randomized. Several slices were cut and five microscopic fields were randomly analyzed blindly moving the stage of the microscope in each animal. The analysis used a video-microscopic system (Olympus BX50) and a test system composed of 36 test points $\left(\mathrm{P}_{\mathrm{T}}\right)$ (Mandarimde-Lacerda 2003): volume density (hepatocytes, sinusoids, steatosis, and hepatic fibrosis) $\mathrm{V}_{\mathrm{v}}=\mathrm{P}_{\mathrm{P}} / \mathrm{P}_{\mathrm{T}}(\%)\left(\mathrm{P}_{\mathrm{P}}\right.$ represents the points hitting the structure).

Numerical density of hepatocyte nuclei was estimated using the optical disector (Sterio 1984) as $\mathrm{Nv}[\mathrm{h}]=\mathrm{Q}^{-} / \mathrm{t} . \mathrm{A}_{\mathrm{T}}$ $1 / \mathrm{mm}^{3}$, where $\mathrm{Q}^{-}$is the number of hepatocyte nuclei seen in focus only in look-up plane, $t$ the thickness of the dissector, and $\mathrm{A}_{\mathrm{T}}$ the test area. The number of hepatocyte nuclei per liver $(\mathrm{N}[\mathrm{h}])$, the number of mononucleated hepatocyte $\mathrm{N}[\mathrm{nh}]$, the binucleated hepatocyte $\mathrm{N}[\mathrm{bh}]$ were estimated as the product of the numerical density of the hepatocyte nuclei by the hepatic volume previously measured (Mandarim-de-Lacerda 2003).

Statistical analysis - The data were statistically analyzed by SPSS software. Groups were compared using the non-parametric Kruskal-Wallis analysis of variance and the post hoc test of Dunn. Values of $p \leq 0.05$ were considered statistically significant (Zar 1999).

\section{RESULTS}

Plasma lipid concentrations and animals biometry Mice fed high-fat diet had TC, HDL-C, LDL-C levels significantly different $(p=0.002, p=0.003, p=0.003)$, respec- 
tively, compared to standard chow group. However, VLDL-c and TG levels were not significantly different between groups of mice (Table II). Mice fed the high-fat $\operatorname{diet}(\mathrm{HFC}$ and IHFC) gained significantly $(\mathrm{p}<0.05)$ more weight than control mice that fed normal diets ( $\mathrm{SC}$ and ISC) (Table II, Fig. 1). No significant difference in liver volume was found $(\mathrm{p}=0.07)$ (Table II).

Liver morphology - Mice fed-high fat diet (HFC and IHFC) have an accumulation of lipids that causing damages to hepatocytes and consequent loss of sinusoids identify, which are not apparent in the control group. To compensate this destruction, a lot of binucleated hepatocytes were found. The livers of infected groups (ISC and IHFC) exhibited schistosomal granuloma (Fig. 2).

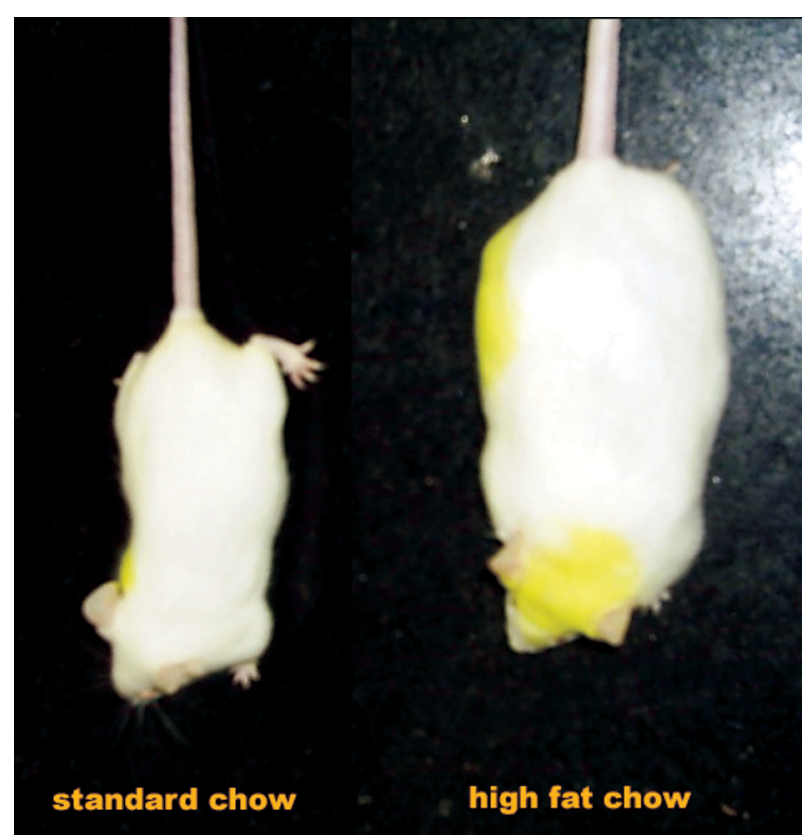

Fig. 1: photomicrograph of the animal fed standard chow or high fat chow.
Hepatocytes - The number of hepatocytes per liver decreased about $50 \%$ in groups IHFC and ISC and HFC when compared with control group (SC) (Figs 3, 4). IHFC mice group presented more binucleated hepatocytes compared to HFC group (by 19\%), ISC group (by 17\%), and SC group (by 6\%) (Fig. 5). The $\mathrm{Vv}[\mathrm{h}]$ was different between SC group (78\%), HFC (48\%), ISC (40\%), and IHFC (37\%) (Fig. 6).

Fat globules - Only livers of fat mice groups exhibited some degree of steatosis. Volume density Vv[st] was larger in HFC group. $\mathrm{Vv}$ [st] was different $(\mathrm{p}=0.0004)$ between HFC (40\%) and IHFC mice groups (10\%) (Fig. 6).

Sinusoids - The Vv[s] was different $(\mathrm{p}=0.003)$ between the control group (SC) $(22 \%)$ and the other groups: HFC (12\%), ISC (12\%), IHFC (10\%) (Fig. 6).

Hepatic fibrosis - Volume density $\mathrm{Vv}[\mathrm{hf}]$ was significant different $(p=0.0007)$ between ISC (48\%), IHFC (44\%), $\mathrm{SC}$ and HFC (0\%) groups (Fig. 6).

\section{DISCUSSION}

This work was aimed at evaluating whether high-fat feeding could structurally affect hepatic alterations in schistosomiasis mansoni-infected mice. Present findings showed that high-fat chow caused overweight, dyslipidemia and liver injury in mice. In rodents, hypercholesterolemia occurs due to increased hepatic cholesterol synthesis and decreased LDL-c clearance, conversion of cholesterol to bile acids, and secretion of cholesterol into the bile (Mohr et al. 2004). Diet-induced obesity causes reduced energy expenditure associated with low leptin sensitivity (Widdowson et al. 1997) that could explain present results of increased body mass and circulating TC, HDL-c and LDL-c levels. The plasma lipoproteins levels observed in the present study, however, fit into the acceptable range of mice (Naveilhan et al. 2002).

Liver performs many essential functions for the body, including absorption of fat in the diet (Michalopoulos \& DeFrances 2005). The metabolic consequence of ingesting a high-fat diet (HFD) is the development of fatty liver

TABLE II

Biometrical data $($ mean $\pm \mathrm{SD})$

\begin{tabular}{lccccc}
\hline & \multicolumn{4}{c}{ Groups } & \\
\cline { 2 - 5 } Parameters & $\mathrm{SC}$ & HFC & ISC & IHFC & Probability \\
\hline $\mathrm{TC}^{a}$ & $146.4 \pm 44.3$ & $205.8 \pm 32.2$ & $100.2 \pm 20$ & $199.8 \pm 52.8$ & $\mathrm{p}<0.05^{b}$ \\
$\mathrm{TG}^{a}$ & $265.0 \pm 41.1$ & $286.0 \pm 29.6$ & $283.0 \pm 51.5$ & $243.8 \pm 23.1$ & $\mathrm{p}>0.05$ \\
$\mathrm{LDL}^{a}$ & $31.6 \pm 24.0$ & $69.8 \pm 34.0$ & $10.0 \pm 9.0$ & $91.0 \pm 43.0$ & $\mathrm{p}<0.05^{b}$ \\
$\mathrm{HDL}-\mathrm{C}^{a}$ & $61.6 \pm 15.5$ & $78.8 \pm 8.3$ & $38.4 \pm 8.3$ & $60.2 \pm 20.3$ & $\mathrm{p}<0.05^{b}$ \\
$\mathrm{VLDL}^{a}$ & $53.1 \pm 8.2$ & $57.2 \pm 5.9$ & $56.6 \pm 10.3$ & $48.8 \pm 4.6$ & $\mathrm{p}>0.05$ \\
$\mathrm{BM}^{21}(\mathrm{~g} / \mathrm{cm})$ & $368.0 \pm 21.0$ & $386.0 \pm 14.0$ & $339.0 \pm 36.0$ & $385.0 \pm 9.0$ & $\mathrm{p}<0.05^{b}$ \\
$\mathrm{BM}^{30}(\mathrm{~g} / \mathrm{cm})$ & $326.0 \pm 8.0$ & $357.0 \pm 7.0$ & $323.0 \pm 24.0$ & $352.0 \pm 10.0$ & $\mathrm{p}<0.05^{b}$ \\
$\mathrm{LV}\left(10^{3} \mathrm{~mm} m^{3}\right)$ & $2.5 \pm 0.2$ & $3.9 \pm 0.9$ & $2.6 \pm 0.3$ & $3.3 \pm 0.8$ & $\mathrm{p}>0.05$ \\
\hline
\end{tabular}

HDL-C: high-density lipoprotein cholesterol; HFC: uninfected mice fed high-fat chow; IHFC: infected mice fed high-fat chow; ISC: infected mice fed standard chow; LDL-C: low-density lipoprotein cholesterol; LV: liver volume (Scherle's method) after 30 weeks of experiment; SC: uninfected mice fed standard chow; TC: total cholesterol; TG: triglycerides; VLDL-C: very-long-density lipoprotein cholesterol; $a$ : plasma concentrations in $\mathrm{mg} / \mathrm{dl} ; \mathrm{BM}^{21}, \mathrm{BM}^{30}$ - Body mass index after 21 and 30 weeks of experiment; $b$ : when compared with the respective control group. 

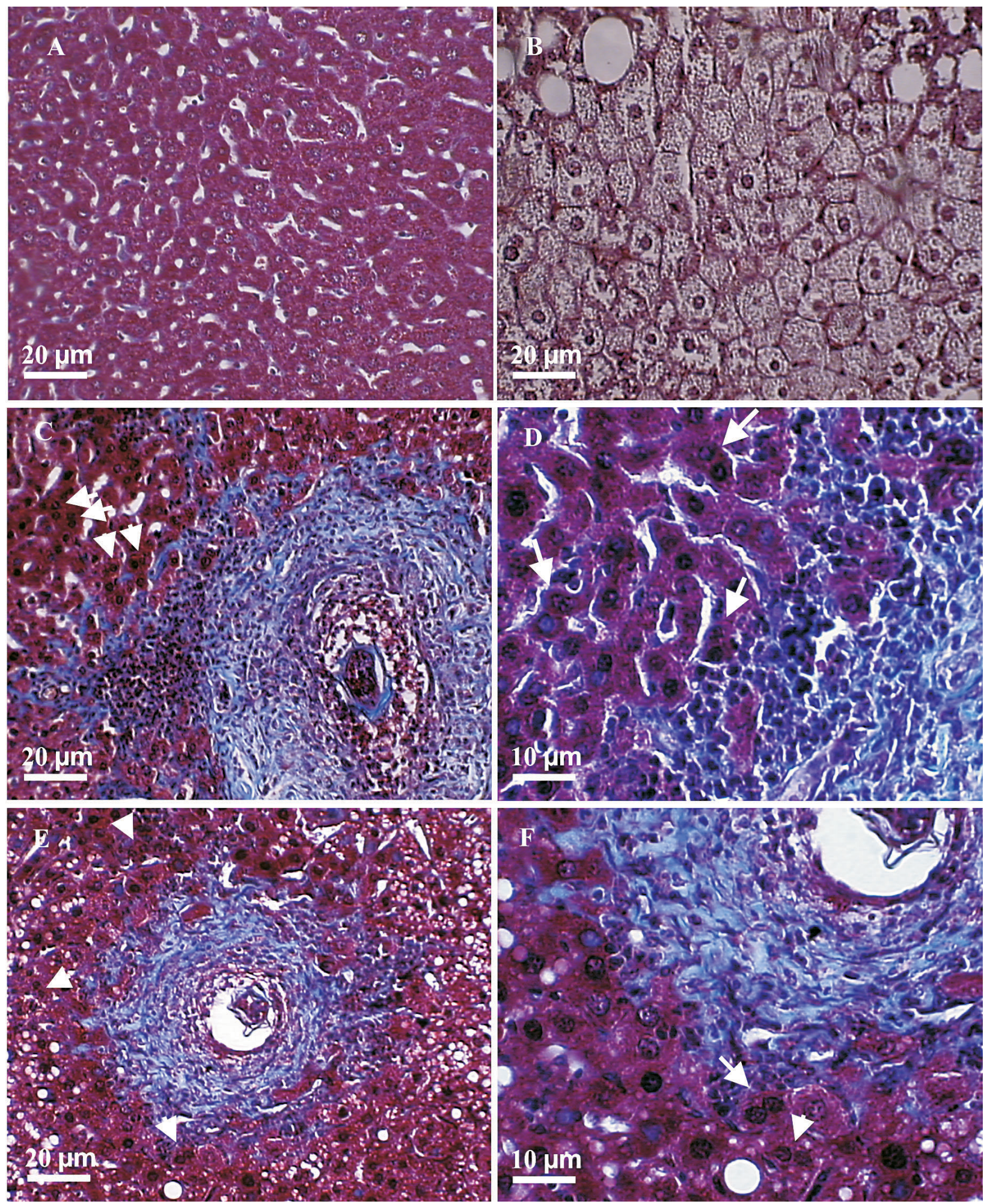

Fig. 2: photomicrographs of the hepatic structure in animals fed standard mice chow (A, C and D) or high fat chow (B, E and F), stained with Masson's trichrome. A: panoramic view of a normal mice (SC group) liver shows the hepatic lobule with plates of hepatocytes and, between them, the hepatic sinusoids; B: panoramic view of an abnormal mice (HFC group) liver. Hepatocytes are paler and bigger due to micro and macrovesicular steatosis that causes disarray of the plates of hepatocytes and consequent loss of sinusoids identify; C: view of a typical schistosomal hepatic showing concentric arrangement of fibers and normal and binucleated hepatocyte (®) around the granuloma (ISC group); D: high magnification of fibrosis, sinusoids and normal and binucleated hepatocyte (®); E: panoramic view showing a schistosomal granuloma, hepatic lobule region with micro and macrovesicular steatosis, altered sinusoids and hepatocytes (normal and binucleated hepatocyte (®) (IHFC group); F: high magnification of hepatocyte to show macrovesicular steatosis destroying cellular structure. To compensate this destruction we found lot of binucleated hepatocytes $(\mathbb{R})$. 


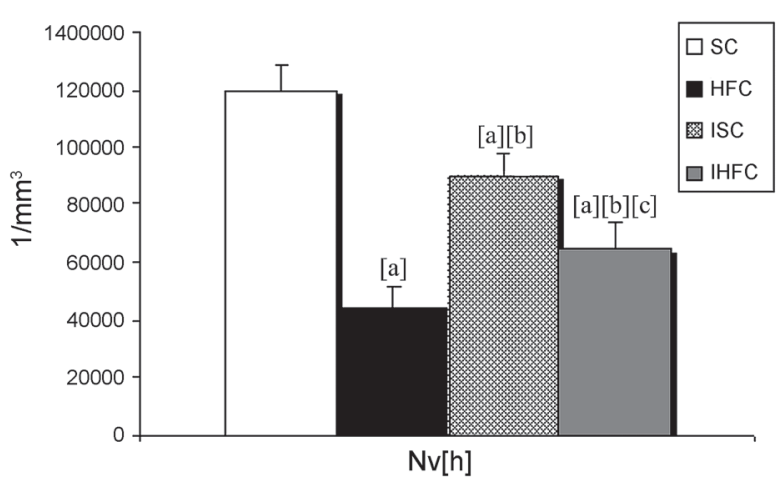

Fig. 3: numerical density of hepatocytes. In signaled cases, when compared, $\mathrm{p} \leq 0.05$, if: [a] when compared with SC group, [b] with HFC group, [c] with ISC group.

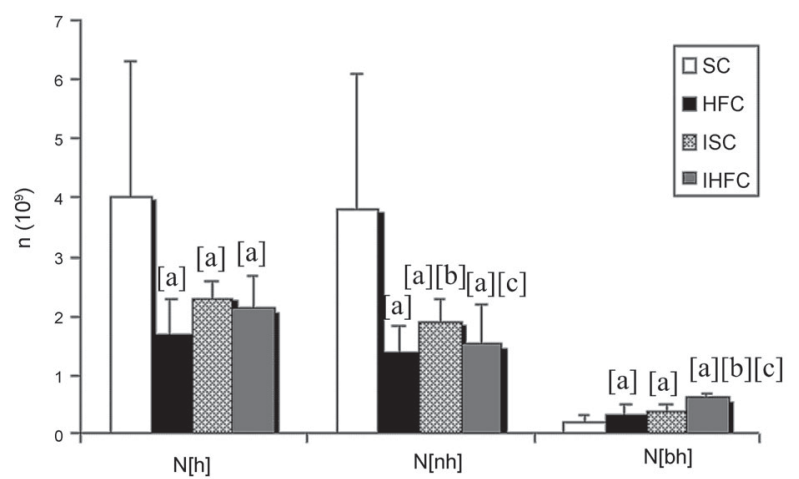

Fig. 4: the absolute number of total hepatocyte $N[h]$, normal hepatocyte $\mathrm{N}[\mathrm{nh}]$ and binucleated hepatocyte $\mathrm{N}[\mathrm{bh}]$. In signaled cases, when compared, $\mathrm{p} \leq 0.05$, if: [a] when compared with $\mathrm{SC}$ group, [b] with HFC group, [c] with ISC group.

disease or steatosis (Biddinger et al. 2005, Li et al. 2005), a histopathologic condition characterized by an excess accumulation of lipids, primarily triacylglycerol (TG), within hepatocytes (Burt et al. 1998). In addition, mice fed highfat acquire hepatic innate immune system abnormalities (Li et al. 2005). Hence, the progression of liver injury in mice fed HFD is of likely pathophysiological relevance.

Hepatocyte in fatty livers is vulnerable to insults (Carmiel-Haggai et al. 2005). Consequently, another concomitant liver disease may provide a synergistic combination of steatosis, cellular adaptation, and oxidative damage that aggravates liver injury (Powell et al. 2005). Therefore, schistosomiasis mansoni infection could overload hepatic injury on the basis of an already pathological situation. Eggs trapped in the liver lead to inflammation (Fallon \& Dunne 1999, Cheever et al. 2002), collagen deposition and fibrous expansion of the portal spaces and intrahepatic portal-vein obstruction (Abath et al. 2006). The literature about liver histological changes in schistosomiasis mansoni is relatively abundant (Andrade et al. 1997, Lenzi et al. 1998, 1999, Baptista \& Andrade 2005). In contrast, quantitative aspects of liver structure have received less attention. The present analysis used point-counting approach and stereology that is considered a technique

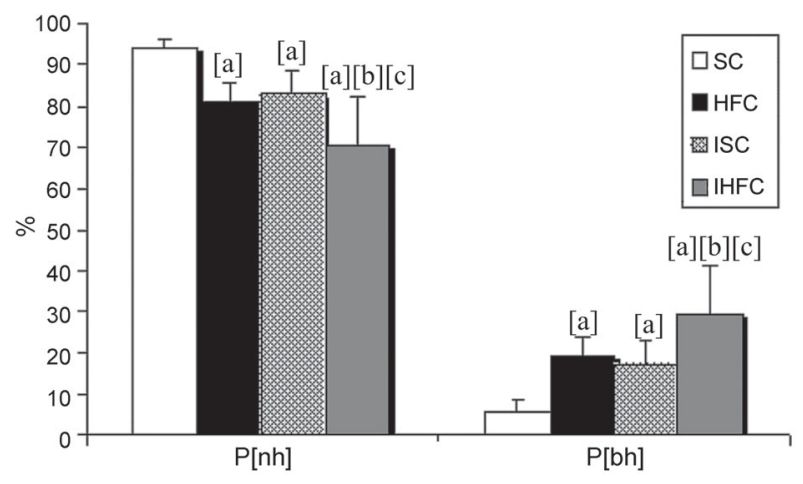

Fig. 5: the percentage of normal hepatocyte $\mathrm{P}[\mathrm{nh}]$ and binucleated hepatocyte $\mathrm{P}[\mathrm{bh}]$. In signaled cases, when compared, $\mathrm{p} \leq 0.05$, if: [a] when compared with SC group, [b] with HFC group, [c] with ISC group.

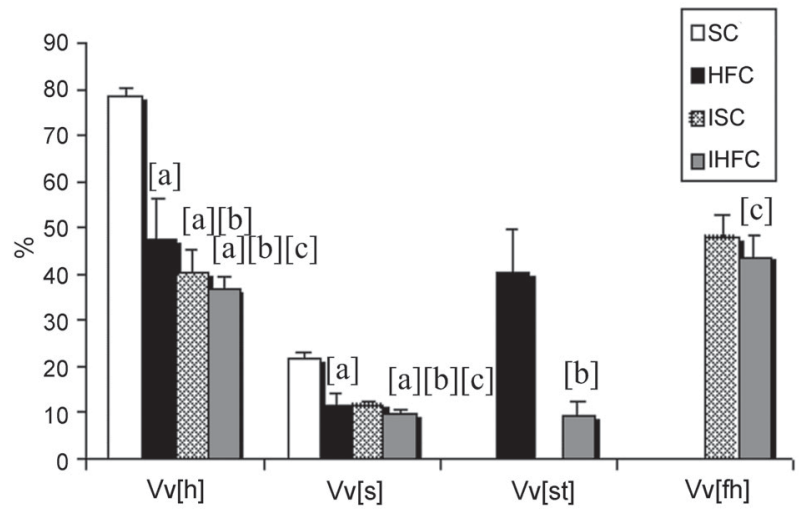

Fig. 6: volume density of hepatic structures and hepatic fibrosis. In signaled cases, when compared, $\mathrm{p} \leq 0.05$, if: [a] when compared with $\mathrm{SC}$ group, [b] with HFC group, [c] with ISC group. of better reproducibility than visual evaluation and should be preferred in estimates of liver damages in scientific studies (Franzen et al. 2005).

Previous study in rat demonstrated that long-term administration of high-fat diet caused hepatic fat accumulation with different degrees of alterations in the hepatocytes and sinusoids (Aguila et al. 2003). In the current study, despite of the similarities between mice groups in their response to high-fat feeding, differences were observed. Stereological parameters regarding hepatocytes indicated quantitative differences among $\mathrm{HFC}$, ISC, and IHFC groups, suggesting that both high-fat diet and schistosomiasis cause damage in liver structure. Several lines of evidence indicate that hepatic steatosis is an important component of the metabolic syndrome (Biddinger et al. 2005). Interestingly, density of fat globules was larger in HFC group when compared with IHFC group, suggesting that schistosomiasis infection decreases lipid accumulation. Because parasite surface-bound host LDL, it may provides the schistosome with cholesterol and other lipids, as well as aid immune avoidance, understanding this process may provide fundamental insights into lipid metabolism and host defense in schistosomes (Furlong \& Caulfield 1988, Tempone et al. 1997, Bica et al. 2000). More- 
over, infected mice submitted to high-fat feeding had smallest density of sinusoids compared with other groups. This also suggests that diet with underline infection lead to sinusoids injury.

Quantification of hepatic fibrosis is important to stage and follow the progression of chronic liver diseases (Friedenberg et al. 2005). Hepatic schistosomiasis induces a compensatory hypertrophy of the hepatic artery, with increased sinusoidal pressure resulting in alterations of hepatic function (Andrade 1986). In this study, the density of hepatic fibrosis changed depending on the diet. The group submitted to a standard chow diet showed greater hepatic fibrosis in comparison with mice fed a highfat diet. It is possible that such findings are associated with differences in the organization of the lattice of collagen fibers built around schistosome eggs. In liver, the schistosomal granuloma is an organized structure, where the three-dimensional arrangement of its fibers, originating from anchorage points serves to provide increased tissue integrity and efficient distribution of soluble compounds and a haptotatic background to the cells (Lenzi et al. 1999).

The liver responds to injury with regulated tissue regeneration every time there is a major loss of hepatic tissue (Michalopoulos \& DeFrances 2005). The rodent partial hepatectomy model is the most extensively used tool for studying the hepatic regenerative response (Rudnick 2005). During partial hepatectomy (PHx) significant morphological, biochemical, and gene expression changes occur in cellular populations of the liver (Michalopoulos $\&$ DeFrances 2005). Because hepatocytes normally remain in proliferative quiescence, they require achieving competence for proliferation. In this initial phase, hepatocytes produce multiple growth regulatory cytokines, including interleukin-6 and tumor necrosis factor (TGF $\alpha)(\mathrm{Zim}-$ mermann 2004). In addition, the state of hepatocytes (quiescent versus proliferative) appears to depend on rapid shifts in balance between signals leading to proliferation and signals leading to mito-inhibition (Michalopoulos \& DeFrances 2005). The expansion phase is chiefly regulated by hepatocyte growth factor (HGF) and transforming growth factor-alfa (TGF $\alpha$ ). The termination phase is mainly mediated by transforming growth factor-beta (TGF $\beta$ ) and activins. Resinusoidalization, formation of the perisinusoidal space of Disse, and the re-synthesis of the perisinusoidal extracellular matrix also take place (Zimmermann 2004).

Some rodent models of nonalcoholic fatty liver evidence that adipogenesis is an important part of the response of hepatocyte during liver regeneration (Farrell \& Thorpe 2005). The effects of chronic exposure to a highfat diet on liver regeneration in mice subjected to partial hepatectomy has been recently studied (DeAngelis et al. 2005). Besides obesity and steatosis, there was a significant impaired liver regeneration in comparison to mice fed standard diet. The investigators concluded that high-fat feeding and steatosis predispose to increased hepatic injury. Normal or only mildly delayed liver regeneration has been reported in other models of diet-induced hepatic steatosis (Zhang et al. 1999, Rao et al. 2001, Picard et al. 2002).
In the current study, diet-induced liver regeneration was observed. Mice fed high-fat diet had greater absolute number and percentage of binucleated hepatocytes than control mice that were fed normal chow. This data suggest that diet-induced hepatic steatosis is a pivotal factor for hepatocyte regeneration, because hepatocytes really need to synthesize fat in order to proliferate (Shteyer et al. 2004).

There are few published papers dealing with hepatic regeneration in murine experimental schistosomiasis in spite of the importance of this disease (Costa et al. 1999). A first observation is that the rodent partial hepatectomy is also used for studying the hepatic regenerative response. Earlier studies demonstrated that extensive schistosomal lesions do not hinder hepatic cell regeneration (Teixeira \& Andrade 1985, Zucoloto et al. 1990). However, nothing is known about the hepatic regeneration in schistosomiasis-infected mice submitted to chronic feeding a high-fat diet. To our knowledge, the current report is the first study connecting hepatic regeneration in schistosomiasis mansoni animal model developing metabolic syndrome induced by HFD. Binucleated hepatocytes were significantly increased in infected mice compared with uninfected control group. This agrees with previous studies indicating that schistosomiasis infection represents a considerable stimulus for the regenerative capacity of the liver only during the acute phase of disease (Costa et al. 1999). Our findings suggest that schistosomiasis mansoni infection indeed can overload hepatic injury on the basis of an already pathological situation (steatosis). The clinical implications of our data may be substantial. As the prevalence of obesity and fatty liver disease continues to increase, the morbidity associated with schistosomiasis also may increase (Rudnick 2005). In conclusion, schistosomiasis mansoni infection with concurrent high-fat diet promotes intensive quantitative changes in hepatic structure, contributing to an increasing on hepatic regeneration.

\section{REFERENCES}

Abath FG, Morais CN, Montenegro CE, Wynn TA, Montenegro SM 2006. Immunopathogenic mechanisms in schistosomiasis: what can be learnt from human studies? Trends Parasitol 22: 85-91.

Aguila MB, Loureiro CC, Mandarim-de-Lacerda CA 2002. Lipid metabolism in rats fed diets containing different types of lipids. Arq Bras Cardiol 78: 25-38.

Aguila MB, Parente LB, Mandarim-de-Lacerda CA 2003. Dietary effect of different high-fat diet on rat liver stereology. Liver Int 23: 363-370.

Andrade ZA 1986. Liver sinusoidal pathology and schistosomiasis. Rev Soc Bras Med Trop 19: 63-65.

Andrade ZA, De Azevedo TM 1987. A contribution to the study of acute schistosomiasis (an experimental trial). Mem Inst Oswaldo Cruz 82: 311-317.

Andrade ZA, Silva LM, de Souza MM 1997. An experimental approach to the pathogenesis of "pipestem" fibrosis (Symmers' fibrosis of the liver). Mem Inst Oswaldo Cruz 92: 699-706. 
Baptista AP, Andrade ZA 2005. Angiogenesis and schistosomal granuloma formation. Mem Inst Oswaldo Cruz 100: 183185.

Bica I, Hamer DH, Stadecker MJ 2000. Hepatic schistosomiasis. Infect Dis Clin North Am 14: 583-604, viii.

Biddinger SB, Almind K, Miyazaki M, Kokkotou E, Ntambi JM, Kahn CR 2005. Effects of diet and genetic background on sterol regulatory element-binding protein-1c, stearoylCoA desaturase 1, and the development of the metabolic syndrome. Diabetes 54: 1314-1323.

Burt AD, Mutton A, Day CP 1998. Diagnosis and interpretation of steatosis and steatohepatitis. Semin Diagn Pathol 15: 246-258.

Carmiel-Haggai M, Cederbaum AI, Nieto N 2005. A high-fat diet leads to the progression of non-alcoholic fatty liver disease in obese rats. Faseb J 19: 136-138.

Carson FL, Martin JH, Lynn JA 1973. Formalin fixation for electron microscopy: a re-evaluation. Am J Clin Pathol 59: 365-373.

Cheever AW, Lenzi JA, Lenzi HL, Andrade ZA 2002. Experimental models of Schistosoma mansoni infection. Mem Inst Oswaldo Cruz 97: 917-940.

Costa G, Cunha-Melo JR, Aguiar BG, Goncalves SC, Toppa NH, Coelho PM 1999. Hepatic regeneration after partial hepatectomy in mice infected with Schistosoma mansoni, at the acute and chronic phases of the disease. Rev Inst Med Trop São Paulo 41: 255-258.

DeAngelis RA, Markiewski MM, Taub R, Lambris JD 2005. A high-fat diet impairs liver regeneration in C57BL/6 mice through overexpression of the NF-kappaB inhibitor, IkappaBalpha. Hepatology 42: 1148-1157.

Fallon PG, Dunne DW 1999. Tolerization of mice to Schistosoma mansoni egg antigens causes elevated type 1 and diminished type 2 cytokine responses and increased mortality in acute infection. J Immunol 162: 4122-4132.

Farrell SR, Thorpe C 2005. Augmenter of liver regeneration: a flavin-dependent sulfhydryl oxidase with cytochrome $\mathrm{c}$ reductase activity. Biochemistry 44: 1532-1541.

Festi D, Colecchia A, Sacco T, Bondi M, Roda E, Marchesini G 2004. Hepatic steatosis in obese patients: clinical aspects and prognostic significance. Obes Rev 5: 27-42.

Franzen LE, Ekstedt M, Kechagias S, Bodin L 2005. Semiquantitative evaluation overestimates the degree of steatosis in liver biopsies: a comparison to stereological point counting. Mod Pathol 18: 912-916.

Friedenberg MA, Miller L, Chung CY, Fleszler F, Banson FL, Thomas R, Swartz KP, Friedenberg FK 2005. Simplified method of hepatic fibrosis quantification: design of a new morphometric analysis application. Liver Int 25: 1156-1161.

Friis H, Andersen CB, Vennervald BJ, Christensen NO, Pakkenberg B 1998. The use of a stereological method to estimate the volume of Schistosoma mansoni granulomas: the effect of zinc deficiency. Ann Trop Med Parasitol 92: 785-792.

Furlong ST, Caulfield JP 1988. Schistosoma mansoni: sterol and phospholipid composition of cercariae, schistosomula, and adults. Exp Parasitol 65: 222-231.

Hogan LH, Wang M, Suresh M, Co DO, Weinstock JV, Sandor
M 2002. CD4+ TCR repertoire heterogeneity in Schistosoma mansoni-induced granulomas. J Immunol 169: 63866393.

Jacobs W, Bogers J, Deelder A, Wery M, Van Marck E 1997. Adult Schistosoma mansoni worms positively modulate soluble egg antigen-induced inflammatory hepatic granuloma formation in vivo. Stereological analysis and immunophenotyping of extracellular matrix proteins, adhesion molecules, and chemokines. Am J Pathol 150: 2033-2045.

Lazzarini AL, Levine RA, Ploutz-Snyder RJ, Sanderson SO 2005. Advances in digital quantification technique enhance discrimination between mild and advanced liver fibrosis in chronic hepatitis C. Liver Int 25: 1142-1149.

Lenzi HL, Kimmel E, Schechtman H, Pelajo-Machado M, Romanha WS, Pacheco RG, Mariano M, Lenzi JA 1998. Histoarchitecture of schistosomal granuloma development and involution: morphogenetic and biomechanical approaches. Mem Inst Oswaldo Cruz 93 (Suppl. 1): 141-151.

Lenzi HL, Kimmel E, Schechtman H, Pelajo-Machado M, Vale BS, Panasco MS, Lenzi JA 1999. Collagen arrangement in hepatic granuloma in mice infected with Schistosoma mansoni: dependence on fiber radiation centers. Braz J Med Biol Res 32: 639-643.

Li Z, Soloski MJ, Diehl AM 2005. Dietary factors alter hepatic innate immune system in mice with nonalcoholic fatty liver disease. Hepatology 42: 880-885.

Lima VL, Sena VL, Stewart B, Owen JS, Dolphin PJ 1998. An evaluation of the marmoset Callithrix jacchus (sagui) as an experimental model for the dyslipoproteinemia of human Schistosomiasis mansoni. Biochim Biophys Acta 1393: 235-243.

Mandarim-de-Lacerda CA 2003. Stereological tools in biomedical research. An Acad Bras Cienc 75: 469-486.

Michalopoulos GK, DeFrances M 2005. Liver regeneration. Adv Biochem Eng Biotechnol 93: 101-134.

Mohr M, Klempt M, Rathkolb B, de Angelis MH, Wolf E, Aigner B 2004. Hypercholesterolemia in ENU-induced mouse mutants. J Lipid Res 45: 2132-2137.

Naveilhan P, Svensson L, Nystrom S, Ekstrand AJ, Ernfors P 2002. Attenuation of hypercholesterolemia and hyperglycemia in ob/ob mice by NPY Y 2 receptor ablation. Peptides 23: 1087-1091.

Picard C, Lambotte L, Starkel P, Sempoux C, Saliez A, Van den Berge V, Horsmans Y 2002. Steatosis is not sufficient to cause an impaired regenerative response after partial hepatectomy in rats. J Hepatol 36: 645-652.

Powell EE, Jonsson JR, Clouston AD 2005. Steatosis: co-factor in other liver diseases. Hepatology 42: 5-13.

Rao MS, Papreddy K, Abecassis M, Hashimoto T 2001. Regeneration of liver with marked fatty change following partial hepatectomy in rats. Dig Dis Sci 46: 1821-1826.

Rudnick DA 2005. Trimming the fat from liver regeneration. Hepatology 42: 1001-1003.

Scherle W 1970. A simple method for volumetry of organs in quantitative stereology. Mikroskopie 26: 57-60.

Shteyer E, Liao Y, Muglia LJ, Hruz PW, Rudnick DA 2004. Disruption of hepatic adipogenesis is associated with impaired liver regeneration in mice. Hepatology 40: 1322-1332. 
Silva LM, Fernandes AL, Barbosa Jr. A, Oliveira IR, Andrade ZA 2000. Significance of schistosomal granuloma modulation. Mem Inst Oswaldo Cruz 95: 353-361.

Stavitsky AB 2004. Regulation of granulomatous inflammation in experimental models of schistosomiasis. Infect Immun 72: $1-12$.

Sterio DC 1984. The unbiased estimation of number and sizes of arbitrary particles using the disector. J Microsc 134 (Pt 2): 127-136.

Teixeira CC, Andrade ZA 1985. Hepatic regeneration following partial hepatectomy in mice infected with Schistosoma mansoni. Braz J Med Biol Res 18: 201-205.

Tempone AJ, Bianconi ML, Rumjanek FD 1997. The interaction of human LDL with the tegument of adult Schistosoma mansoni. Mol Cell Biochem 177: 139-144.
Widdowson PS, Upton R, Buckingham R, Arch J, Williams G 1997. Inhibition of food response to intracerebroventricular injection of leptin is attenuated in rats with diet-induced obesity. Diabetes 46: 1782-1785.

Zar JH 1999. Biostatistical Analysis, Prentice Hall, Upper Saddle River, 663 pp.

Zhang BH, Weltman M, Farrell GC 1999. Does steatohepatitis impair liver regeneration? A study in a dietary model of non-alcoholic steatohepatitis in rats. J Gastroenterol Hepatol 14: 133-137.

Zimmermann A 2004. Regulation of liver regeneration. Nephrol Dial Transplant 19 (Suppl. 4): iv6-10.

Zucoloto S, da Silva JC, de Castro e Silva Junior O, Ganzaga EZ, Dal Fabbro AL 1990. Hepatic regeneration after hepatectomy in schistosomatic fibrosis. Int $J$ Exp Pathol 71: 465-468. 